\title{
Universiteit
}

Leiden

The Netherlands

\section{Characterisation factors for life cycle impact assessment of sound emissions}

Cucurachi, S.; Heijungs, R.; Cucurachi S., Heijungs R.

\section{Citation}

Cucurachi, S., \& Heijungs, R. (2013). Characterisation factors for life cycle impact assessment of sound emissions. Science Of The Total Environment, 468-469, 280-291. doi:10.1016/j.scitotenv.2013.07.080

Version: $\quad$ Publisher's Version

License: $\quad$ Licensed under Article 25fa Copyright Act/Law (Amendment Taverne)

Downloaded from: https://hdl.handle.net/1887/21806

Note: To cite this publication please use the final published version (if applicable). 


\title{
Characterisation factors for life cycle impact assessment of sound emissions
}

\author{
S. Cucurachi ${ }^{*}$, R. Heijungs \\ Institute of Environmental Sciences (CML), Leiden University, P.O. Box 9518, 2300 RA Leiden, The Netherlands
}

\section{H I G H L I G H T S}

- Characterisation factors for the impact of sound emissions on humans are proposed.

- Different levels of specification are available (i.e. spatial, temporal, physical).

- The factors are applicable to any sound emitting source located in Europe.

- Archetypal situations of emission are modelled (e.g. urban location, day, $8000 \mathrm{~Hz}$ ).

- The factors are ready to be implemented in LCA databases and case studies.

\section{A R T I C L E I N F O}

\section{Article history:}

Received 21 March 2013

Received in revised form 19 June 2013

Accepted 23 July 2013

Available online 10 September 2013

Editor: P. Kassomenos

\section{Keywords:}

Noise

Noise impacts

Life cycle

LCIA

LCA

Annoyance

\begin{abstract}
A B S T R A C T
Noise is a serious stressor affecting the health of millions of citizens. It has been suggested that disturbance by noise is responsible for a substantial part of the damage to human health. However, no recommended approach to address noise impacts was proposed by the handbook for life cycle assessment (LCA) of the European Commission, nor are characterisation factors $(\mathrm{CFs})$ and appropriate inventory data available in commonly used databases. This contribution provides CFs to allow for the quantification of noise impacts on human health in the LCA framework. Noise propagation standards and international reports on acoustics and noise impacts were used to define the model parameters. Spatial data was used to calculate spatially-defined CFs in the form of 10-by-10-km maps. The results of this analysis were combined with data from the literature to select input data for representative archetypal situations of emission (e.g. urban day with a frequency of $63 \mathrm{~Hz}$, rural night at $8000 \mathrm{~Hz}$, etc.). A total of 32 spatial and 216 archetypal CFs were produced to evaluate noise impacts at a European level (i.e. EU27). The possibility of a user-defined characterisation factor was added to support the possibility of portraying the situation of full availability of information, as well as a highly-localised impact analysis. A Monte Carlo-based quantitative global sensitivity analysis method was applied to evaluate the importance of the input factors in determining the variance of the output. The factors produced are ready to be implemented in the available LCA databases and software. The spatial approach and archetypal approach may be combined and selected according to the amount of information available and the life cycle under study. The framework proposed and used for calculations is flexible enough to be expanded to account for impacts on target subjects other than humans and to continents other than Europe.
\end{abstract}

(c) 2013 Elsevier B.V. All rights reserved.

\section{Introduction}

\subsection{Scope}

Life cycle assessment (LCA; ISO 14042, ISO, 2000) aims at quantifying in a holistic and integrated way how each phase of the life cycle of a product contributes to impacts such as climate change, eutrophication,

\footnotetext{
Abbreviations: i, frequency index; c, time index; f, location index; $\mathrm{CF}$, Characterisation factor [number of people-Pa/W]; D, Directivity [dB]; EF, Effect factor [number of people]; $\mathrm{FF}$, Fate factor [Pa/W]; Lw, Background sound power level [decibel]; Nf, Number of exposed subjects; AC, archetypal context; SC, Spatial context.

* Corresponding author. Tel.: + 31715271478.

E-mail address: cucurachi@cml.leidenuniv.nl (S. Cucurachi).
}

and resource depletion among others (Rebitzer et al., 2004; Pennington et al., 2004). The necessity of quantifying the impact of noise emissions from any life cycle has been stressed since the first days of the formalisation of the methodology (Heijungs et al., 1992).

Noise has for long been recognised as a stressor. Scientific studies have shown that the impacts of noise are not limited to psychological effects, such as annoyance, but also to physiological effects, such as cardiovascular diseases (WHO, 2011; Babisch, 2006). As a result of traffic noise, one in three individuals in Europe is affected by environmental noise during the daytime, and one in five at night (WHO, 2011). It has been quantified that disturbance by noise is responsible for a substantial part of the damage to human health, when measured in disabilityadjusted life years (DALY; Müller-Wenk, 2004). 
The LCA handbook of the European Commission (ILCD, 2010) included noise as one of the impact categories with high priority for methodological development, because no recommended approach to address noise impacts could be proposed by the handbook. To date all practical applications of LCA (case studies, databases, software) do not include noise as an impact category. To a large extent this is due to a lack of a good method and to a limited investigation of the relevant literature in acoustics and impact assessment of sound. Cucurachi et al. (2012), after an analysis of epidemiological data and a study of the LCA literature on noise, proposed a new theoretical framework. It aimed at presenting a rigorous formal way of characterisation of noise impacts, which is in line with the characterisation model and the overall theoretical structure used for other impact categories in LCA.

\subsection{Problem definition}

Sound and noise are two categories of the same physical phenomenon. However, sound emissions are not necessarily determining noise. Noise is the result of unwanted or intolerable sound, to which one is not voluntarily exposed. From a physical point of view, sound emissions are associated with a momentary compression and decompression of sound waves through a medium, which lead to a change of pressure and a shifting of molecules in the medium. Thus, sound emissions are temporary and expire in a limited amount of time. Sound propagates and dissipates while it travels through air (i.e. the only medium considered by this contribution).

Several factors (e.g. meteorological conditions) intervene in and attenuate sound emissions, while other factors (e.g., directivity) orientate them. In the work of Cucurachi et al. (2012), such factors were included in the theoretical framework indicated for the calculation of the fate of and the effect factor for noise impacts. However, the framework provided only a theoretical model, with model parameters to be filled in. The aim of this new contribution is to operationalise the model, implement these factors and use them for the calculation of characterisation factors for noise impacts.

The environmental mechanisms involved in the propagation and attenuation of sound emission, and the relative noise impact are complex, non-linear and highly dependent upon local circumstances. The acoustic phenomena and parameters which are relevant in the proposed framework are, in fact, strictly related to a particular topography and to specific local conditions. To reach greater accuracy, propagation of sound is usually calculated by either taking a fully empirical approach, or assuming specific conditions of propagation (e.g. a flat area with short grass). In an ideal world, LCA should be able to portray any possible context of (sound) emission and to account for the effects of those emissions on the target subjects. In practice, sound levels need to be predicted for different heights above ground, various types of foliage (e.g. tree belts), walls, houses, etc. For a fully-empirical local noise assessment, this can be done. In LCA, however, a life cycle typically spans thousands of locations, so a site-specific assessment is not feasible. This constrains the modeller to face a situation in which one has to choose between the use of highly-specific spatially-defined data, or a situation in which it is necessary to assume representative conditions for the archetypal compartments of emission. Even though the level of accuracy may be greater when location-specific data is considered, spatially-defined variables are not uncertainty-free, nor is the amount of information available to practitioners sufficient to use it to describe the specific life cycle under consideration.

\subsection{Research focus}

The method described in the following sections is based on the established standards of propagation of sound from static or moving sources, such as ISO 9613-1, ISO 9613-2 (ISO, 1993; ISO, 1996), as well as on the recommended approach for the calculation of sound emission and propagation at a European level (European Commission, 2012). Data was processed and scaled to allow for the calculation of characterisation factors for noise, both in the form of ready-to-be-used maps at a European scale, and in the form of archetypal dimensions of emissions. The special case of indoor "occupational" sound emissions was defined only as an archetypal situation of emission. It was decided to use spatially-defined parameters (i.e. GIS map or raster data) to compile characterisation factors in the form of maps in a spatially-defined context. The outcome of this process was used to define archetypal situations of emissions, which used central nominal values for calculations. The use of spatially-defined CFs allowed for the selection of central values in the most appropriate range.

This contribution fills the gap of the absence of noise as an impact category in LCA and presents CFs for noise impacts at a European level (i.e. EU27), which can be used by practitioners, provided the inventory (i.e., sound emission) data are available. The factors produced are, in fact, ready to be implemented in the available LCIA databases and software. The framework proposed and used for calculations is flexible enough to be expanded to account for impacts on target subjects other than humans and to continents other than Europe.

In the following section, the model is described in detail. The results of the modelling decisions are shown in Section 3 and discussed in Section 4. The Supplementary material of this contribution provides a detailed description of the equations and modelling choices (Supplementary material 1 ), and their results (Supplementary materials 2, 3 and 4).

\section{The noise impact assessment model: elaboration of the framework}

\subsection{The background model and the life cycle inventory phase}

Most sounds emitted by a source are complex and fluctuate in amplitude and frequency. The relationships between sound energy level and frequency are required for the meaningful analysis of a sound spectrum. Cucurachi et al. (2012) propose to analyse the sound emitted by a source according to the one-third octave bands centre frequencies in which its spectrum can be split into. The distinction among frequencies allows not only depicting and following the ability of our hearing system to perceive the frequency composition of a sound, but also allows accommodating any context of emission. If certain centre-frequency bands are dominant for a specific source, or limited information is available, selected centre-frequency bands may be chosen instead of others (e.g. 63 to $500 \mathrm{~Hz}$, instead of 2000 to $8000 \mathrm{~Hz}$ ). Similarly, if the model had to be expanded for the consideration of impacts on target systems other than humans, the centrefrequency ranges of interest may be differently chosen. No differentiation among sources (e.g. static or moving) was proposed in Cucurachi et al. (2012), but it recommended the differentiation of emissions at the inventory level according to the frequency of emission (e.g. $63 \mathrm{~Hz}$ ), the location (e.g. rural and urban), and the time of the day (i.e. day, evening, and night. The characterisation of the frequency, the time, and the location of the sound emission is also crucial in the later impact assessment of the relative noise perceived by the target subjects.

In Cucurachi et al. (2012), 8 centre-octave frequency bands are considered in line with the ISO 9613-2 (1996) standard on the attenuation of sound during propagation outdoors. As for the location of emission, they were defined by analysing the result of the spatial analysis described in Section 2.2, and in accordance with the literature on the determination of archetypal situations of emission (Jolliet et al., 2005; Curran, 2012). Time specifications refer to the common practice of distinguishing between day, evening, and night time of sound emissions that are commonly used to allow for a different perception of sound by humans according to the time of the exposure. The case of the undefined compartment of emission (e.g., time or otherwise) was introduced in all cases to account for limited information in the hand of the practitioner who would have to use the CFs. 
The sound emission is not only spatially differentiated as is common for many impact categories in LCA, but also temporally and physically differentiated. The collection of information during the inventory phase can allow for a better characterisation of sound, thus potentially a better quantification of the relative noise impacts. At the inventory level, Cucurachi et al. (2012) prescribed taking into account the sound power level of each source and converting it into sound energy, using the physical properties of sound. International standards (e.g. ISO 9613-2; ISO, 1996) and reports (e.g. WHO, 2001) provide suitable and readily-usable information to calculate the sound power level of any source, be it static or mobile. An accurate reference is the CNOSSOS reference report (European Commission, 2012) which provides indications on how to calculate the sound power emission of any type of source, discriminating among noise caused by the so-called road traffic (e.g. light motor vehicles, medium motor vehicles, etc.), railway traffic, air traffic, and industrial sources.

Following ISO9614-1 (ISO, 1993), in CNOSSOS the sound power level is defined as "in-situ" or in "semi-free field". Sound power includes effects of reflections and other specifications in the immediate vicinity of the source (e.g. the surface under the source). The parameters are specified per class of sources and also for combinations of similar sources (e.g. traffic conditions). Sound power level (in decibel, dB) can be back-transformed to the relative sound power using the reference value of $10^{-12}$ watts $(\mathrm{W})$, and then the relative sound energy to be reported in the inventory table can be calculated by applying the methodology reported by Cucurachi et al. (2012).

The time a source is active in a life cycle can be calculated based on the production rate of the system (i.e. $\mathrm{kg} / \mathrm{s}$ ) and the relative output (i.e. $\mathrm{kg}$ ). Similarly, for a life cycle involving a transportation stage the production rate would be the speed in $\mathrm{km} / \mathrm{h}$, and the output the number of $\mathrm{km}$ driven relatively to the functional unit under consideration. The formula for the calculation of the $\mathrm{LCI}$ item $\mathrm{m}_{\mathrm{i}, \mathrm{c}, \mathrm{f}}$ is

$\mathrm{m}_{i, c, f}=\mathrm{W}_{i, c, f} \times$ time $_{c, f}$,

Where $i$ is the centre-frequency band, $c$ indicates the time, $f$ the location, $\mathrm{W}_{i, c, f}$ in joule/s is the sound power of the source under consideration calculated according to the indication of the CNOSSOS reference report, and time $e_{c f}$ is the time calculated as a function of the production rate of the system and the relative output.

A didactic example may be here of help. If the system under study has to produce e.g. 1 ton of product, and the relative production rate is, e.g., 1000 tons/year, the production rate of the system would be of $3.17 \mathrm{E}-5$ tons/s. The value of time ${ }_{c, f}$ would be in total of $31,536 \mathrm{~s}$ (i.e., as a ratio between the functional unit and the production rate), to be further specified in terms of time and location. For the time, it should be considered that, for a system at continuous production, the emission would take place during the day for $12 / 24$ of the time, in the evening for $4 / 24$ of the time, and at night for $8 / 24$ of the time. Alternative production rates or production systems with shifts may be used. Time can be similarly apportioned to different locations (i.e. archetypal or geographical).

Let us consider the case of a sound power level of $60 \mathrm{~dB}$ at a centreband frequency of $1000 \mathrm{~Hz}$, as calculated following the indications of the CNOSSOS report (European Commission, 2012). Similarly, we could calculate sound power levels at other centre-band frequencies. For a matter of simplicity of this didactic example, the value of the sound power level has not any further specification than the frequency specification $i$. In real applications, further local conditions of time and locations may be considered if necessary. We can back convert the sound power level of $60 \mathrm{~dB}$ to a sound power in joule/s, using the reference sound power level of $10^{-12} \mathrm{~dB}$ (ISO 9613-1, 1993). Applying the formula reported in Eq. (1) we can calculate the inventory items $\mathrm{m}_{i, c_{f} f}$ in joules that will function as inventory item in the inventory table relative to the example under study. The items to be inventoried would be $0.015768 \mathrm{~J}$ for the day, $0.005256 \mathrm{~J}$ for the evening, and $0.010512 \mathrm{~J}$ for the night. As we will see in the next section, these values will be multiplied by the appropriate $\mathrm{CFs}$, to calculate the human noise impact at a midpoint level.

\subsection{Definition of spatial parameters and archetypal situations of emission}

The environmental mechanisms involved in the propagation and attenuation of sound emissions, and the relative noise impacts are typically complex, non-linear and highly-dependent upon local circumstances. In order to operationalise the impact assessment model described in Cucurachi et al. (2012) in line with ISO 9613-1 and ISO 9613-2 (ISO, 1993, 1996) and the CNOSSOS reference report (European Commission, 2012), this contribution introduces a series of input parameters, constants and variables (see Table 2.1) that will be detailed in the following sections and in Supplementary material 1.

The parameters defined in Cucurachi et al. (2012) were firstly spatially-defined in raster maps (see Supplementary material 1), which were meaningfully combined to obtain spatially-explicit CFs for EU27 (Eurostat, 2007) using ArcGIS 10 (ESRI, 2011).

The following dimensions were defined:

- octave: $63 \mathrm{~Hz}$ ( 44 to $88 \mathrm{~Hz}$ ), $125 \mathrm{~Hz}$ ( 88 to $177 \mathrm{~Hz}$ ), $250 \mathrm{~Hz}$ (177 to $354 \mathrm{~Hz}$ ), $500 \mathrm{~Hz}$ ( 354 to $707 \mathrm{~Hz}$ ), $1000 \mathrm{~Hz}$ (707 to $1414 \mathrm{~Hz}$ ), 2000 ( 1414 to $2828 \mathrm{~Hz}$ ), $4000 \mathrm{~Hz}$ (2828 to $5656 \mathrm{~Hz}$ ), $8000 \mathrm{~Hz}$ (5656 to $11312 \mathrm{~Hz})$;

Table 2.1

Parameters and variables used in the model.

\begin{tabular}{|c|c|c|}
\hline $\begin{array}{l}\text { Input } \\
\text { parameter }^{\mathrm{a}}\end{array}$ & Description $^{\mathrm{b}}$ & Unit/expression $^{c}$ \\
\hline Lw & Background sound power level & $\mathrm{dB}$ \\
\hline $\mathrm{T}$ & Temperature & ${ }^{\circ} \mathrm{C}$ \\
\hline $\mathrm{Rh}$ & Relative humidity & $\%$ \\
\hline$P$ & Local pressure & $\mathrm{Pa}$ \\
\hline h & Height of propagation & $\mathrm{m}$ \\
\hline d & Distance from source to receiver & $\mathrm{m}$ \\
\hline S & Surface of propagation & $\mathrm{m}^{2}$ \\
\hline $\mathrm{Nf}$ & Population & Number $^{\mathrm{d}}$ \\
\hline$\rho$ & Population density & Number \\
\hline Wamb & Background sound power & $\mathrm{W}$ \\
\hline $\operatorname{Pr}$ & Attenuation factor for protective measures & $\mathrm{dB}$ \\
\hline$\psi$ & Rate of use of protective measures & $\%$ \\
\hline$\alpha \mathrm{m}$ & Room absorption parameter & Number \\
\hline $\mathrm{C}_{\mathrm{ref}}$ & Ratio of conversion factors & Number \\
\hline D & Directivity of sound propagation & $\mathrm{dB}$ \\
\hline C & Constant transformation factor $\mathrm{dB}$ to Watt & $\mathrm{W}$ \\
\hline$P_{\text {ref }}$ & Reference ambient pressure & $\mathrm{Pa}$ \\
\hline $\mathrm{P}_{\text {rel }}$ & Relative pressure & Number \\
\hline Kelvin & Conversion factor from ${ }^{\circ} \mathrm{C}$ to ${ }^{\circ} \mathrm{K}$ & Number \\
\hline $\mathrm{T}_{\text {ref }}$ & Reference ambient temperature & ${ }^{\circ} \mathrm{C}$ \\
\hline $\mathrm{T}_{\text {kel }}$ & Local temperature in Kelvin & ${ }^{\circ} \mathrm{K}$ \\
\hline $\mathrm{T}_{\text {rel }}$ & Relative temperature & number \\
\hline $\mathrm{T}_{01}$ & Triple-point isotherm temperature & ${ }^{\circ} \mathrm{K}$ \\
\hline $\mathrm{H}$ & Molar concentration of water vapour & Number \\
\hline fro & Nitrogen relaxation frequency as in ISO 9613-1 & $\mathrm{Hz}$ \\
\hline frn & Oxygen relaxation frequency as in ISO 9613-1 & $\mathrm{Hz}$ \\
\hline$\alpha a t m$ & $\begin{array}{l}\text { Attenuation factor due to atmospheric } \\
\text { conditions }\end{array}$ & $\mathrm{dB} / \mathrm{m}$ \\
\hline $\mathrm{rc}$ & Sound absorbing characteristics of a room & $\mathrm{m}^{2}$ \\
\hline $\mathrm{R}$ & Sound absorbing characteristics of a room & $\mathrm{dB}$ \\
\hline$\alpha$ & Frequency penalty & $\mathrm{dB}$ \\
\hline$\beta$ & Time penalty & $\mathrm{dB}$ \\
\hline Aatm & Attenuation due to atmospheric conditions & $\mathrm{dB}$ \\
\hline Adiv & Attenuation due to divergence & $\mathrm{dB}$ \\
\hline Aground & Attenuation due to ground conditions & $\mathrm{dB}$ \\
\hline Apr & $\begin{array}{l}\text { Attenuation due to the use of protective } \\
\text { measures }\end{array}$ & $\mathrm{dB}$ \\
\hline Aextra & Attenuation due to other factors & $\mathrm{dB}$ \\
\hline
\end{tabular}

a Symbol of parameters used in the model.

b Description of the parameter or model variable.

c Physical unit of the parameter or expression used to measure the quantity.

d Dimensionless parameters, either a ratio of quantities or simply a unitless number. 
- time: day ( 7 am to $7 \mathrm{pm}$ ), evening ( $7 \mathrm{pm}$ to $11 \mathrm{pm}$ ), night (11 pm to $7 \mathrm{am})$, and unspecified.

CFs in the spatial format were calculated using ArcGIS 10 (ESRI, 2011). A total of $32 \mathrm{CFs}$ were produced. The resulting raster maps are provided as Supplementary material 1 to this contribution.

Single parameters were obtained from various sources (see Table 2.1), and adapted for the calculations described in the following sections.

The ETRS89 Lambert Azimuthal Equal Area (Annoni et al., 2003) was defined for all raster layers and a cell size of $10 \mathrm{~km}$ was selected in line with the available data. Given the different origin of all sources, processing tools in ArcGIS were used to obtain raster maps with the suitable level of spatial definition. Map algebra (Burrough and McDonnell, 1998) was, then, used to implement the calculations defined in the Supplementary material. For those parameters whose value would not change at different locations, a constant raster was defined and used as an input for calculations (see Table 2.2).

The results obtained were used to elaborate archetypal situations of emissions, i.e. urban, suburban, rural, industrial and indoor. Statistical data was used for the definition and differentiation of parameters amongst the defined dimensions. In all the cases when it was not possible to find suitable statistical support, the data available in a map format and spatially-defined was analysed and provided a sufficient basis upon which to develop calculations. The sources of the data are reported in Table 2.3. The parameters used for the protective measures and the rate of use of protective measures were defined only in the case of indoor emissions.

Parameters and constants were combined together in a spreadsheet compiled using Microsoft Excel (see Supplementary material 3).

The following dimensions were defined for this context:

- octave: $63 \mathrm{~Hz}$ (44 to $88 \mathrm{~Hz}$ ), $125 \mathrm{~Hz}$ ( 88 to $177 \mathrm{~Hz}$ ), $250 \mathrm{~Hz}$ (177 to $354 \mathrm{~Hz}$ ), $500 \mathrm{~Hz}$ (354 to $707 \mathrm{~Hz}$ ), $1000 \mathrm{~Hz}$ (707 to $1414 \mathrm{~Hz}$ ), 2000 ( 1414 to $2828 \mathrm{~Hz}$ ), $4000 \mathrm{~Hz}$ ( 2828 to $5656 \mathrm{~Hz}$ ), $8000 \mathrm{~Hz}$ (5656 to $11312 \mathrm{~Hz}$ )

- location: urban area, suburban (i.e. residential) area with no nearby traffic concern, rural area with no nearby traffic, industrial or commercial area, indoor, and unspecified;

- time: day, evening, night, and unspecified.

Section 3 and the Supplementary material (see Supplementary materials 2 and 3 ) provide the full set of factors for the defined dimensions in both spatial and archetypal contexts.

\subsection{Background conditions of exposure}

The degree to which environmental noise affects humans (and other species) depends on the ambient background conditions of the soundscape they are used to, as well as, to a certain extent, on the sensitivity of each individual to sound changes above the background. It can be demonstrated that human activities generate sound at growing intensities with growing population levels (US-EPA, 1974; Stewart et al.,

Table 2.2

Specific parameters and resolution used in the spatial context.

\begin{tabular}{lll}
\hline Parameter & Source of the data & Spatial resolution \\
\hline Ambient sound level [dB] & EASA (2009) & $10 \mathrm{~km}$ \\
Temperature $\left[{ }^{\circ} \mathrm{C}\right]$ & Hijmans et al. (2005) & $1 \mathrm{~km} \mathrm{ca}$. \\
Relative humidity at $2 \mathrm{~m}[\%]$ & Saha et al. $(2010)$ & $38 \mathrm{~km} \mathrm{ca}$. \\
Ambient pressure $[\mathrm{kPa}]$ & ISO $(1993,1996)$ & Set to $10 \mathrm{~km}$ \\
Average propagation height [m] & This report & Set to $10 \mathrm{~km}$ \\
Distance [m] & This report & Set to $10 \mathrm{~km}$ \\
Number of exposed subjects [number] & EASA (2009) & $10 \mathrm{~km}$ \\
Elevation [m] & Jarvis et al. (2008) & $30 \mathrm{~m}$ \\
\hline
\end{tabular}

1999). Sound emissions are usually quantified in terms of a pressure level in $\mathrm{dB}$ or scaled to the sensitivity to sound of the human hearing system (in $\mathrm{dBA}$ ). Alternatively, the sound pressure may be denoted by a physical natural quantity (i.e. measured in pascals).

The background sound environment of a specific location may be also measured by its sound power level. Availability of data in both cases is limited. We use the sound power to indicate the physical natural quantity (i.e. measured in watt), while sound power level here denotes the sound power ratio (in $\mathrm{dB}$ ) to a reference quantity of 1 picowatt (pW).

A study by EASA (2009) reports sound pressure level using yet another measure: L95, in dBA, for day, evening, and night. L95 defines the sound pressure level exceeded for $95 \%$ of the time at a given location (i.e. only in 5\% of the time the sound pressure level was less than L95). Background sound pressure levels, as calculated by EASA, may be defined as the sound pressure level at a location from a number of more or less identifiable sound sources when the direct sound from prominent sources is excluded (EASA, 2009).

In the context of acoustic ecology it would be defined as the reference soundscape of a specific location. Using a more appropriate LCA terminology, the background sound pressure level may be defined as the background sound of a location which was not yet perturbed by the functional unit under study, whose sound power has been inventoried in the LCI (i.e. life cycle inventory) table.

L95 represents a sound pressure level in dBA, which may be transformed to a sound power in $\mathrm{W}$. We are, in fact, interested in the sound power of the environment under study. In other terms, we assume that the environment where the emission takes place is itself a source of sound emission with a certain sound power. This "theoretical" source is a composition of sources already perturbing the environment before the functional unit is active in it. The value of the background sound power is in reality different across different centre-frequency ranges, as it was the sound power inventoried in the LCI. Due to the limited availability of data, we considered the value of the background sound environment as equal across all centre-frequency bands. For the details of the calculation of the L95 value we refer to the full BANOERAC report (EASA, 2009).

The CFs for midpoint noise impacts were defined in Cucurachi et al. (2012) according to the classical LCIA characterisation scheme (Pennington et al., 2004), as shown in Eq. (1):

$\mathrm{CF}_{i, c, f}=\sum_{i, c, f}\left(\mathrm{FF}_{i, c, f} \times \mathrm{EF}_{i, c, f}\right)$.

Thus, the CFs for each of the defined spatial and archetypal situations of emission were calculated by multiplying the FF and

Table 2.3

Specific parameters and sources used in the archetypal context.

\begin{tabular}{|c|c|}
\hline Parameter & Source of the data (elaboration from) \\
\hline Ambient sound level [dB] & EASA (2009) \\
\hline Temperature $\left[{ }^{\circ} \mathrm{C}\right]$ & Hijmans et al. (2005) \\
\hline Humidity [\%] & Saha et al. (2010) \\
\hline Ambient pressure $[\mathrm{kPa}]$ & ISO (1993) \\
\hline $\begin{array}{l}\text { Average propagation } \\
\text { height [m] }\end{array}$ & This report \\
\hline Distance $[\mathrm{m}]$ & This report \\
\hline $\begin{array}{l}\text { Population density } \\
\left.\text { [people } / \mathrm{km}^{2}\right]\end{array}$ & $\begin{array}{l}\text { Eurostat, 2007; Analysis of spatially-defined data in the } \\
\text { spatial context }\end{array}$ \\
\hline Reference area $\left[\mathrm{km}^{2}\right]$ & $\begin{array}{l}\text { Eurostat, 2007; Analysis of spatially-defined data in the } \\
\text { spatial context }\end{array}$ \\
\hline $\begin{array}{l}\text { Number of exposed } \\
\text { subjects }\end{array}$ & $\begin{array}{l}\text { Eurostat, 2007; Analysis of spatially-defined data in the } \\
\text { spatial context }\end{array}$ \\
\hline Use of protective measures & Concha-Barrientos et al. (2004) \\
\hline $\begin{array}{l}\text { Rate of use of protective } \\
\text { measures }\end{array}$ & Concha-Barrientos et al. (2004) \\
\hline
\end{tabular}


the EF at a certain centre-frequency (i), time (c), and location (f). The quantity which expresses the $\mathrm{CF}$ is person $\times \mathrm{Pa} / \mathrm{W}$, which would correspond to $\mathrm{s} * \mathrm{~m}^{-3}$ using the SI standard units (Heijungs, 2005). If we consider that a sound emission, i.e. $\mathrm{m}_{i, c, f}$, is inventoried in units of sound energy (in J), the noise impact on humans (HN) can be expressed by the quantity person $\times \mathrm{Pa} * \mathrm{~S}$, or using the SI unit $\mathrm{kg} / \mathrm{m} * \mathrm{~s}$.

The background conditions of a situation of exposure constitute the basis for the calculation of the fate factor (FF) described in Cucurachi et al. (2012):

$\mathrm{FF}_{i, c, f}=\frac{\mathrm{C}_{\mathrm{ref}}}{\sqrt{\mathrm{Wamb}_{c, f}}} \times 10^{\left(\mathrm{D}_{\mathrm{c}, \mathrm{f}}-\mathrm{A}_{i, c, f}\right) / 20}$.

The FF is measured in $\mathrm{Pa} / \mathrm{W}$ and defines the conversion of a source sound power in watt (W) to a target sound pressure in pascal (Pa). The fate factor reflects a marginal increase in the total ambient sound power of octave-band $i$ at time $c$, and at location $f$ due to the fact that a functional unit was introduced into the system, evaluated at the background level $\mathrm{Wamb}_{c f}$, taken into consideration the directivity of sound $\left(D_{c f}\right)$ and the various possible attenuations $A_{i, c f}$. No differentiation for centre-octave band was considered for the background, due to a limited availability of suitably differentiated data. The detailed elaboration of the calculations of the parameters considered for the FF, including the background sound power, is provided in Section 2 of Supplementary material 1 of this contribution.

The effect factor was defined by Cucurachi et al. (2012) as:

$\mathrm{EF}_{i, c, f}=\mathrm{N}_{\mathrm{f}} \times 10^{\left(\alpha_{i}+\beta_{c}\right) / 20}$.

The unit of the effect factor is person. $\mathrm{N}_{f}$ represents the population size at the exposure compartment $f$ at a certain time of the day $c, \alpha_{i}$ is the penalty (in $\mathrm{dB}$ ) to be added to account for the A-level scale (ISO, 1996), $\beta_{c}$ represents the weighting of the sound emission (in $d B$ ) for the time of the day the emission took place. All parameters and modelling choices are described in Supporting Material 1 to this contribution.

\subsection{Indoor/localised occupational sound emissions}

The CF defined for the calculation of outdoor emissions was extended to the case of sound emissions taking place indoors (see Section 3 of Supplementary material 1 ). The expansion refers to the definition of an indoor/localised occupational compartment of sound emissions (indoor compartment, from now on). It models the exposure to sound emissions which take place in an indoor environment (e.g. a print shop, a production line in a factory) or to sound emissions which are localised at a specific site (e.g. a construction site). The sound emissions considered here can be defined as "occupational". Therefore, they are specifically oriented at investigating the effects of sound emissions (and noise) on e.g., operators of plants, builders, musicians and, in general, all the categories of workers operating with equipment which produces a sound energy of constant or variable intensity and which are subject to serious health burdens (Concha-Barrientos et al., 2004; Stewart et al., 2011).

We extended the fate factor described in Cucurachi et al. (2012) to the indoor compartment with the introduction of a term $\mathrm{R}$, which represents the refraction of sound indoors. The fate factor may be rewritten as:

$\mathrm{FF}_{i, c, f}=\frac{\mathrm{C}_{r e f}}{\sqrt{\mathrm{Wamb}_{c, f}}} \times 10^{\left[\mathrm{D}_{c, f}+\mathrm{R}_{i, f}-\mathrm{A}_{i, c, f}\right] / 20}$.

The unit of the fate factor is $\mathrm{Pa} / \mathrm{W}$ and maintains the exact same meaning as described in Section 3. $R$ represents the reverberant component of sound in a space (i.e. room or localised site), measured in $\mathrm{dB}$. It expresses the acoustic properties of a room (or site), as a function of its specific absorption properties and its surface (Schroeder, 2007).

The effect factor defined by Cucurachi et al. (2012) still holds for the indoor compartment of emissions. In this case, the main difference is the interpretation of the day/evening/night penalty $\beta_{\mathrm{c}}$. In the indoor compartment, in fact, it does not refer to the sleep disturbance of individuals, since they are at work and typically not asleep. The penalty here refers to the disruption of the regular biological clock as determined by evening and night working hours (WHO, 2001). The value of Nf reported in the formula for the effect factor (see Supplementary material 1) represents in the indoor case the number of workers exposed to the sound emission.

\section{Results: characterisation factors and sensitivity analysis}

\subsection{Definition and quantification of characterisation factors for noise impacts on humans}

A total of 248 CFs was calculated for the defined archetypal and spatial contexts, based on the modelling decisions previously described and detailed in Supplementary material 1 to this contribution. The CFs are representative of a vast array of possible conditions of emission.

To support also the needs of a practitioner that would have complete information on all sound emissions in a life cycle, we introduced an extra $\mathrm{CF}$ in the system, in order to leave the user the possibility of defining a "user-defined" context of emission. If enough information is available, one could directly input the location-specific parameters into the model, and have a customised characterisation factor as a result. According to the information available, the practitioner may choose to use 10-by-10-km maps and/or archetypes for different phases of a life cycle, or, alternatively, define site-specific customised conditions. The calculation sheet for the development of localised user-defined CFs is provided in Supplementary material 4.

\subsubsection{CFs under archetypal conditions}

The fixed parameters reported in Table 3.1, allowed for the calculation of all the archetypal CFs, and are representative of the full set of dimensions defined in Section 2.1. The case of either unspecified frequency ranges, or unspecified time, or unspecified space, and all possible permutations of the three cases also needed to be defined. In some cases it was decided to take a regular mean or a weighted (i.e. with a probability index) value of parameters across dimensions. Given the impossibility of averaging several values of the background sound power level across different dimensions, due to the logarithmic scale used for the measurement of the parameters, a pessimistic approach was considered and the maximum value in all cases was selected. The underlying assumption is that the protection of the health of the target should be paramount also at the modelling phase, thus the background levels shall be in all cases the worst among day, evening and night conditions.

The following assumptions were made:

- Unspecified frequency: in this case, the central $1000 \mathrm{~Hz}$ frequency was selected for the calculations as it is the central frequency range for which no extra penalty has to be added in the calculation of sound emissions in dBA (ISO, 1996). This frequency band is central in the sound spectrum and provides a sufficient representation of a sound, if unspecified. Input parameters for time and place did not change.

- Unspecified time: an average value of $7.5 \mathrm{~dB}$ was considered for penalty $\beta$ for day, evening and night emissions. For the calculation of the other parameters, values were dimensioned according to the probability of emissions taking place during different parts of the day. It was decided to adopt a pessimistic view over reality, and therefore the highest probability-weight was attached to "night-parameters", then to "evening parameters", and a lower weight was assigned to 
Table 3.1

Parameters defined for the archetypal case.

\begin{tabular}{|c|c|c|c|c|c|c|c|c|c|c|c|c|c|}
\hline Place & Time & Wamb [dB] & $\mathrm{T}\left[{ }^{\circ} \mathrm{C}\right]$ & $\mathrm{Rh}[\%]$ & $\mathrm{P}[\mathrm{Pa}]$ & $\mathrm{h}[\mathrm{m}]$ & $\mathrm{d}[\mathrm{m}]$ & $\rho\left[\right.$ person $\left./ \mathrm{m}^{2}\right]$ & $\mathrm{S}\left[\mathrm{m}^{2}\right]$ & Nf [people] & $\operatorname{Pr}[\mathrm{dB}]$ & $\psi$ & $\alpha_{\mathrm{m}}$ \\
\hline Urban & Day & 77 & 20 & 30 & 101325 & 3 & 10 & 200 & 20 & 4000 & - & - & - \\
\hline Urban & Evening & 82 & 16 & 60 & 101325 & 3 & 10 & 375 & 20 & 7500 & - & - & - \\
\hline Urban & Night & 84 & 12.8 & 60 & 101325 & 3 & 10 & 450 & 20 & 9000 & - & - & - \\
\hline Urban & Unspecified & 84 & 15.2 & 54 & 101325 & 3 & 10 & 377.5 & 20 & 7550 & - & - & - \\
\hline Suburban & Day & 69 & 20 & 30 & 101.325 & 3 & 10 & 66.7 & 30 & 2000 & - & - & - \\
\hline Suburban & Evening & 75 & 16 & 60 & 101.325 & 3 & 10 & 133.4 & 30 & 4000 & - & - & - \\
\hline Suburban & Night & 75 & 12.8 & 60 & 101.325 & 3 & 10 & 133.4 & 30 & 4000 & - & - & - \\
\hline Suburban & Unspecified & 75 & 15.2 & 54 & 101.325 & 3 & 10 & 120 & 30 & 3600 & - & - & - \\
\hline Rural & Day & 62 & 20 & 40 & 101325 & 3 & 100 & 50 & 10 & 500 & - & - & - \\
\hline Rural & Evening & 68 & 16 & 70 & 101325 & 3 & 100 & 100 & 10 & 1000 & - & - & - \\
\hline Rural & Night & 68 & 12.8 & 70 & 101325 & 3 & 100 & 100 & 10 & 1000 & - & - & - \\
\hline Rural & Unspecified & 68 & 15.2 & 64 & 101325 & 3 & 100 & 90 & 10 & 900 & - & - & - \\
\hline Industrial & Day & 84 & 20 & 30 & 101325 & 3 & 10 & 66.7 & 30 & 2000 & - & - & - \\
\hline Industrial & Evening & 82 & 16 & 60 & 101325 & 3 & 10 & 50 & 30 & 1500 & - & - & - \\
\hline Industrial & Night & 78 & 12.8 & 60 & 101325 & 3 & 10 & 33.4 & 30 & 1000 & - & - & - \\
\hline Industrial & Unspecified & 84 & 15.2 & 54 & 101325 & 3 & 10 & 45 & 30 & 1350 & - & - & - \\
\hline Indoor & Day & 63 & 25 & 40 & 101325 & 3 & 1 & 0.033333 & 300 & 10 & 5 & 0.3 & 0.05 \\
\hline Indoor & Evening & 61 & 25 & 40 & 101325 & 3 & 1 & 0.026667 & 300 & 8 & 5 & 0.3 & 0.05 \\
\hline Indoor & Night & 58 & 25 & 40 & 101325 & 3 & 1 & 0.02 & 300 & 6 & 5 & 0.3 & 0.05 \\
\hline Indoor & Unspecified & 63 & 25 & 40 & 101325 & - & 1 & 0.024667 & 300 & 10 & 5 & 0.3 & 0.05 \\
\hline Unspecified & Day & 84 & 20 & 32.5 & 101325 & 3 & 32.5 & 94.5 & 22.5 & 2125 & - & - & - \\
\hline Unspecified & Evening & 82 & 16 & 62.5 & 101325 & 3 & 32.5 & 155.6 & 22.5 & 3500 & - & - & - \\
\hline Unspecified & Night & 84 & 12.8 & 62.5 & 101325 & 3 & 32.5 & 166.7 & 22.5 & 3750 & - & - & - \\
\hline Unspecified & Unspecified & 84 & 15.2 & 52.5 & 101325 & 3 & 32.5 & 138.9 & 22.5 & 3125 & & & \\
\hline
\end{tabular}

"day-parameters". The maximum background sound power level was chosen.

- Unspecified place: the values of the system parameters were averaged across the 4 different outdoor places of emissions, differentiated per day, evening and night, with unaltered values for the frequency. The maximum background sound power level was chosen.

- Unspecified time and place: the values of the system parameters were averaged, without any additional weight, across places and times of sound emission considering the 12 different outdoor contexts of emissions. Emissions across places and time were assumed to be equally probable. Emissions taking place indoors were excluded from the calculations, in light of the definition given of the indoor compartment in Section 2.4. The maximum background sound power level was chosen across the 12 different outdoor contexts.

- Unspecified frequency and time: the values of the system parameters were averaged across day, evening and night for each of the defined places of emission. The maximum background sound power level across day, evening, and night was chosen.

- Unspecified frequency and unspecified space: the central $1000 \mathrm{~Hz}$ frequency was selected for the frequency, together with an average of all-day, all-evening and all-night values respectively. The maximum background sound power level of all-day, all-evening and all-night values, respectively, was chosen.

- Unspecified frequency, unspecified time and unspecified space: the central $1000 \mathrm{~Hz}$ frequency was selected for the frequency, and the values of all other parameters were averaged across 12 possible outdoor combinations of dimensions. The maximum sound power level across all the possible outdoor combinations was chosen.

The results of the calculations of the CFs for the 248 possible combinations of the dimensions of sound emissions are reported in Supplementary material 3 to this contribution.

If we focus on sound emissions at the central frequency of $1000 \mathrm{~Hz}$ (in Fig. 3.1), it is possible to notice that the highest impact relates to emissions taking place indoors, and at night, while those taking place during the day in a rural area are the least impacting. The case of unspecified emissions at an unspecified time scores lower than emissions taking place during the day.

The trends reported for the lowest available octave band of $63 \mathrm{~Hz}$ follow a similar trend as described above for emissions at $1000 \mathrm{~Hz}$. Fig. 3.2 reports the CFs for emissions in all archetypal compartments at $63 \mathrm{~Hz}$.

At urban locations and at day time the CFs change at varying frequencies (Fig. 3.3), and the highest impact results at $2000 \mathrm{~Hz}$.

\subsubsection{Maps of CFs for EU27}

In the spatial context, 32 maps of CFs with a $10-\mathrm{km}^{2}$ grid were produced (see Supplementary material 1). They refer to emissions taking place in EU27. Raster data was collected and analysed for all the defined parameters. CFs are provided for eight centre-frequencies (i.e. from 63 to $8000 \mathrm{~Hz}$ ) for day, evening, night and unspecified time. In this case, the value of Wamb for the unspecified case was calculated as a mean of the Wamb value for day, evening, and night.

For the case of unspecified frequency of emission, we recommend considering the use of the CFs calculated at the central frequency of $1000 \mathrm{~Hz}$

We will focus the analysis on emissions at $63 \mathrm{~Hz}$ and compare those taking place during day, evening, night or during an unspecified time (Fig. 3.4). Following the colouring scale, the least affected areas are shown in green, while the most affected are represented in dark red. From the comparison of the maps it is clear that metropolitan areas are the most sound-intensive locations, regardless of the time of the emission.

Areas around bigger cities (e.g. Greater London area) are the ones which show the highest values of CFs. Areas with CFs values close to zero, or equal to zero, correspond to areas where attenuations are so dominant to attenuate any effect of the sound emission. The model adopted shows sensitivity to changes in emissions at different centrefrequency ranges. The mean for CFs at $63 \mathrm{~Hz}$ during day time is 1757.05 person $\times \mathrm{Pa} / \mathrm{W}$, with a standard deviation of 2634.63 person $\times \mathrm{Pa} / \mathrm{W}$. CFs for emissions taking place at night have the highest impact, with an average of 7098.74 person $\times \mathrm{Pa} / \mathrm{W}$ and a standard deviation of 9134.29 person $\times \mathrm{Pa} / \mathrm{W}$. During the evening the $\mathrm{CFs}$ at $63 \mathrm{~Hz}$ have a mean of 2070.34 person $\times \mathrm{Pa} / \mathrm{W}$ and a standard deviation of 2827.88 person $\times \mathrm{Pa} / \mathrm{W}$. In the case of unspecified time of emission, a mean of 
Characterization factor [person-Pa/W]

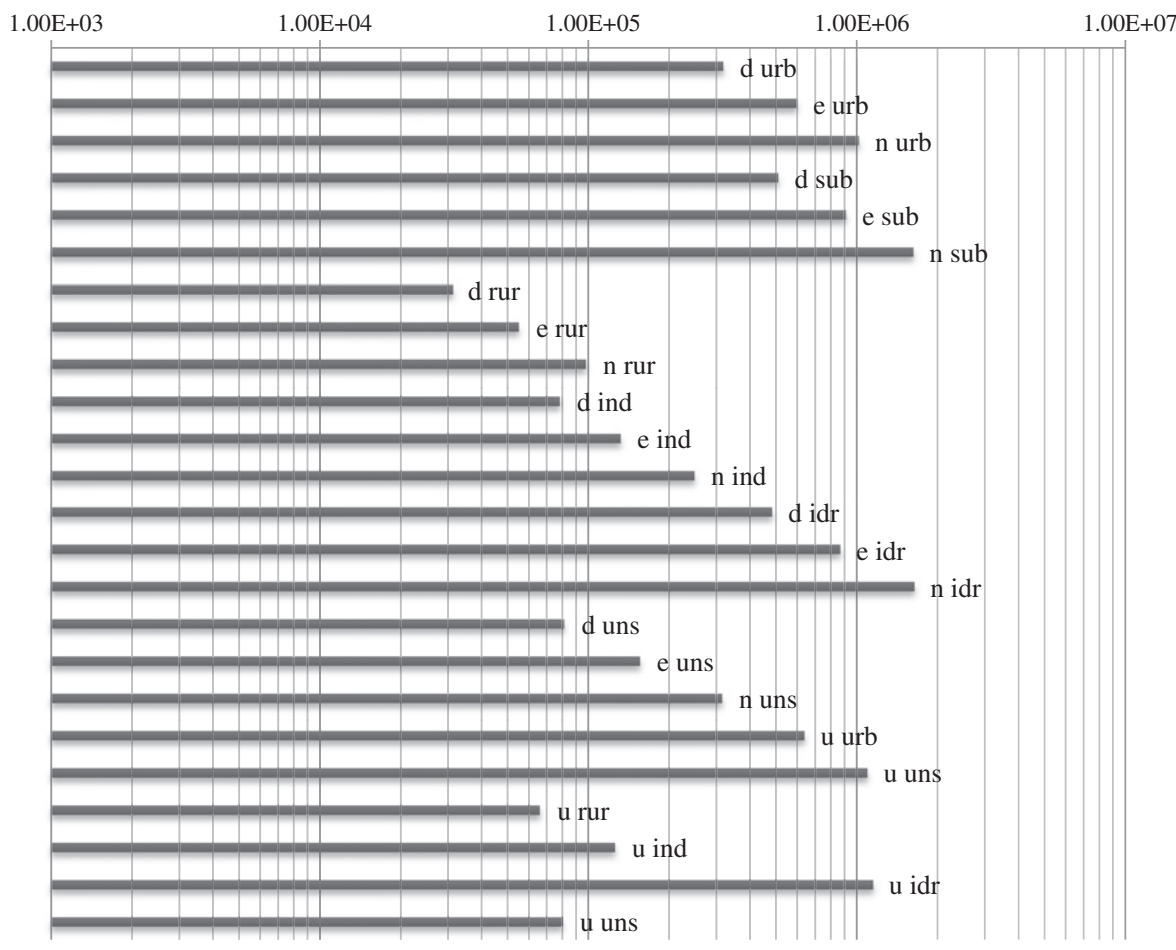

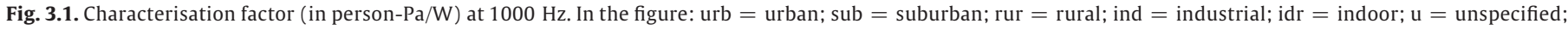
$\mathrm{d}=$ day; $\mathrm{e}=$ evening; $\mathrm{n}=$ night.

2650.87 person $\times \mathrm{Pa} / \mathrm{W}$ was calculated, with a standard deviation of 3632.74 person $\times \mathrm{Pa} / \mathrm{W}$.

At the same frequency, i.e. $63 \mathrm{~Hz}, \mathrm{CFs}$ for day and evening have in all cases a lower value than CFs for night and unspecified time. In Fig. 3.5 the difference is shown graphically. The highest differences are visible (in red) around areas with higher population density and higher background sound levels.

\subsection{Global sensitivity analysis applied to the noise impact model}

For the calculation of CFs in both archetypal and spatial cases, it was necessary to fix factors to a central value, either using data from the literature or extrapolating data from the spatial analysis. We are conscious that this decision introduces extra uncertainty into the overall model. While it can be accepted that uncertainty is an intrinsic feature of complex models (Couclelis, 2003), it does not exclude that much can be done to manage and resolve uncertainties where possible. As stated before in this report, spatial calculations are also the results of assumptions and of the extension of characteristics defined for a specific area to a greater or smaller area of reference. Therefore, they are also uncertain.

We decided to corroborate the proposed model and calculations by applying global sensitivity analysis (i.e. considering at once the full range of input factors). For each parameter a sample distribution was chosen as shown below (Table 3.2). We used the Monte Carlo method (Caflisch, 1998) with quasi-random sampling to calculate 1000 samples of each of the thirteen uncertain input factors considered in the noise LCIA model. The sampling technique was selected to avoid clusters and gaps, which may occur in samples generated randomly (Saltelli et al., 2008). The quasi-random samples are random in the sense that they are distributed uniformly across the entire sample space, but the selection algorithm keeps the newly selected points away from the already-selected ones, thus avoiding the phenomenon of discrepancy (i.e. the lumpiness of a sequence of points in a multidimensional space; Saltelli et al., 2008).
Sensitivity analysis was conducted and the noise impact framework was implemented in the software SIMLAB (Saltelli et al., 2004). The variance-based method extended Fourier amplitude sensitivity testing (eFAST, Saltelli et al., 2004, 2008 pp. 164-166) was used to study how the variance of the output of the proposed model would depend on the uncertain input factors (Saltelli et al., 2008). Variance-based methods are based on the decomposition of the variance of a model output such as $\mathrm{V}(\mathrm{Y})=\mathrm{V}\left[\mathrm{E}\left(\mathrm{Y} \mid \mathrm{X}_{\mathrm{j}}\right)\right]+\mathrm{E}\left[\mathrm{V}\left(\mathrm{Y} \mid \mathrm{X}_{\mathrm{j}}\right)\right]$, for any generic input variable $X_{j}$ (Tarantola et al., 2002). For every input variable, eFAST provides both the first-order sensitivity index $\left(S_{j}\right.$, i.e. the direct contribution to the variance of each parameter) and the total-order sensitivity index of each input parameter $\left(\mathrm{S}_{\mathrm{T}}\right.$, i.e. the sum of all the sensitivity indices, including all the interaction effects, involving that parameter). Table 3.3 shows the first and total order indices for the noise impact model calculated using eFAST. Each of the first order indices, i.e. $S_{j}$, indicates by how much the output variance could be reduced if any input $X_{j}$ could be fixed to a nominal value (Saltelli et al., 2008), thus it is equal to $\mathrm{V}\left[\mathrm{E}\left(\mathrm{Y} \mid \mathrm{X}_{\mathrm{j}}\right)\right] / \mathrm{V}(\mathrm{Y})$. The total sensitivity index $\mathrm{S}_{\mathrm{Tj}}$ is a measure of the overall effect of factor $X_{j}$ on the output, including also all the interactions. It corresponds to the expected variance that is left when all factors are fixed (Saltelli et al., 2008); thus, $\mathrm{S}_{\mathrm{Tj}}=\mathrm{V}\left[\mathrm{E}\left(\mathrm{Y} \mid \mathrm{X}_{-\mathrm{j}}\right)\right] / \mathrm{V}(\mathrm{Y})$, where $\mathrm{X}_{\mathrm{j}}$ indicates that all factors are considered but $\mathrm{X}_{\mathrm{j}}$ (Tarantola et al., 2002). The calculation of $S_{\mathrm{Tj}}$ allows identifying non-influential factors in a model, rather than prioritising the most influential ones.

The indices were calculated both for the final CFs but also for the EF and FF. For the EF, the penalty $\beta$ has the highest $S$ index. For instance, the result would suggest that the size of the penalty matters in the overall result, therefore the model is sensitive to the extra values in $\mathrm{dB}$ added to day, evening and night emissions. The directivity of sound (D), the background sound power ( $\mathrm{LW}$ ), and the distance from source to receiver (d) contribute to most of the variance of the FF. The uncertainty of the attenuation factor included in the model could be reduced if the direction of propagation of sound, the actual background sound power at the location, and the actual distance were known. In this case, the sum of the $S_{j}$ s does not equal to 1 , which suggests higher order interactions 
Characterization factor [person-Pa/W]

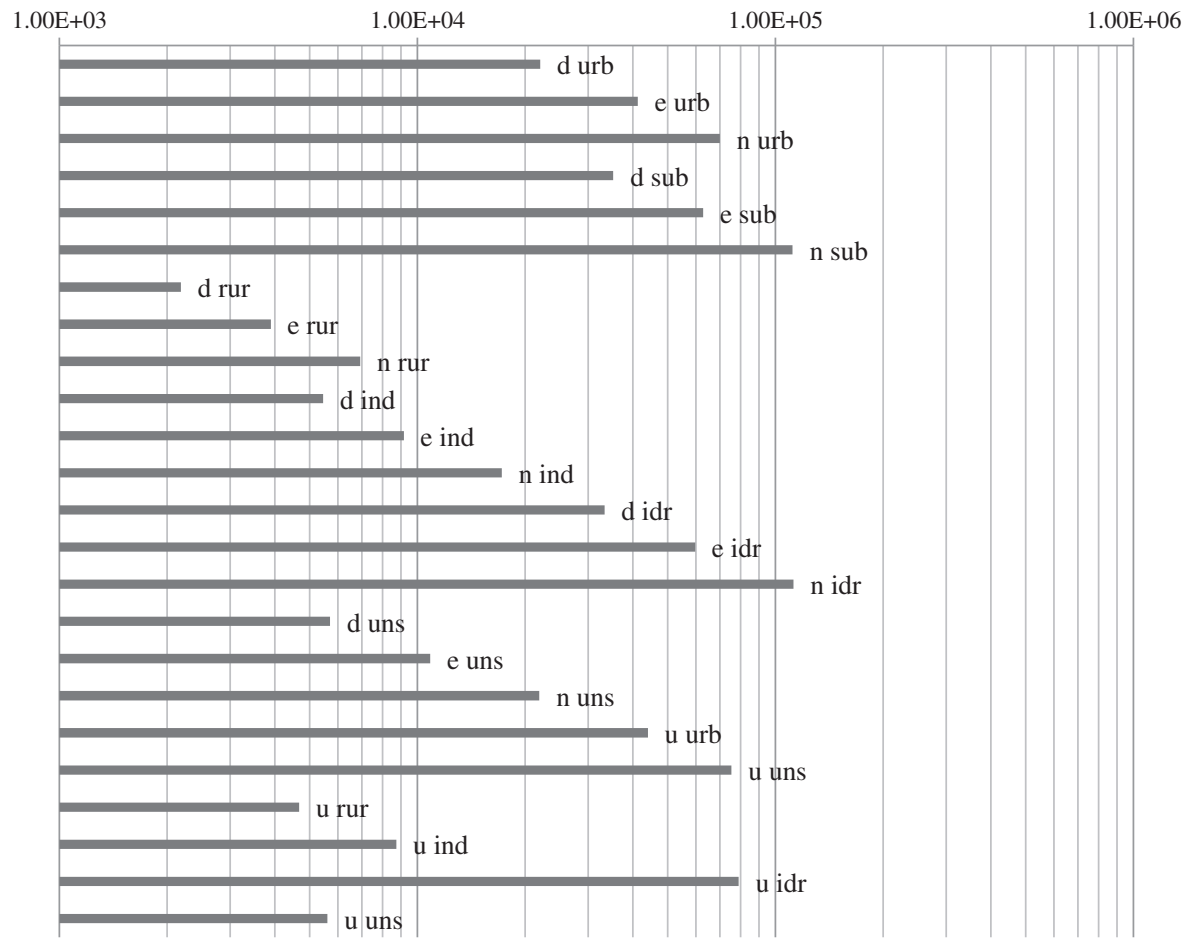

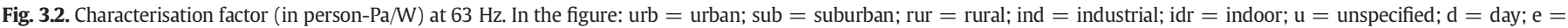
evening; $\mathrm{n}=$ night

among parameters, which suggests that the model is non-additive and non-linear (Saltelli et al., 2008).

As for the $\mathrm{CF}$, which is a product of the FF and the he EF, a similar set of parameters resulted as being statistically important, with the addition of the frequency of emissions (Freq) appearing to be the most relevant values.

The $\mathrm{S}_{\mathrm{Ti}}$ (Table 3.3) confirms that higher-order interactions are present and need to be taken into account for the complete understanding of the model. As Saltelli et al. (1997) propose, a set of input parameters with total sensitivity index greater than 0.8 can be regarded as 'very important', between 0.5 and 0.8 as 'important', between 0.5 and 0.3 as 'unimportant', and less than 0.3 'irrelevant'. In the case of our model, interactions highlight how all the included parameters are important, because of the higher order interactions between them. The distance $d$ from the source to the receiver is still the most influential value, together with the directivity index $\mathrm{D}$ and the penalty $\beta$ (i.e. $\mathrm{S}_{\mathrm{Ti}}=0.89$ ). The frequency of the sound emission comes right after with a $\mathrm{S}_{\mathrm{T}}$ of 0.88 .

\subsection{A possible transition to the endpoint}

So far we have dealt with a model that stops at the midpoint of the impact pathway. Sound emissions have been characterised using the impact assessment model detailed in Cucurachi et al. (2012). The results relate to the sound pressure that, for the time the functional unit under study is active in the product system under study, each individual experiences at a certain location, time of the day, and with a certain frequency of emission (see Heijungs and Suh, 2002 on the computational structure of LCA). In order to more easily compare the impacts from

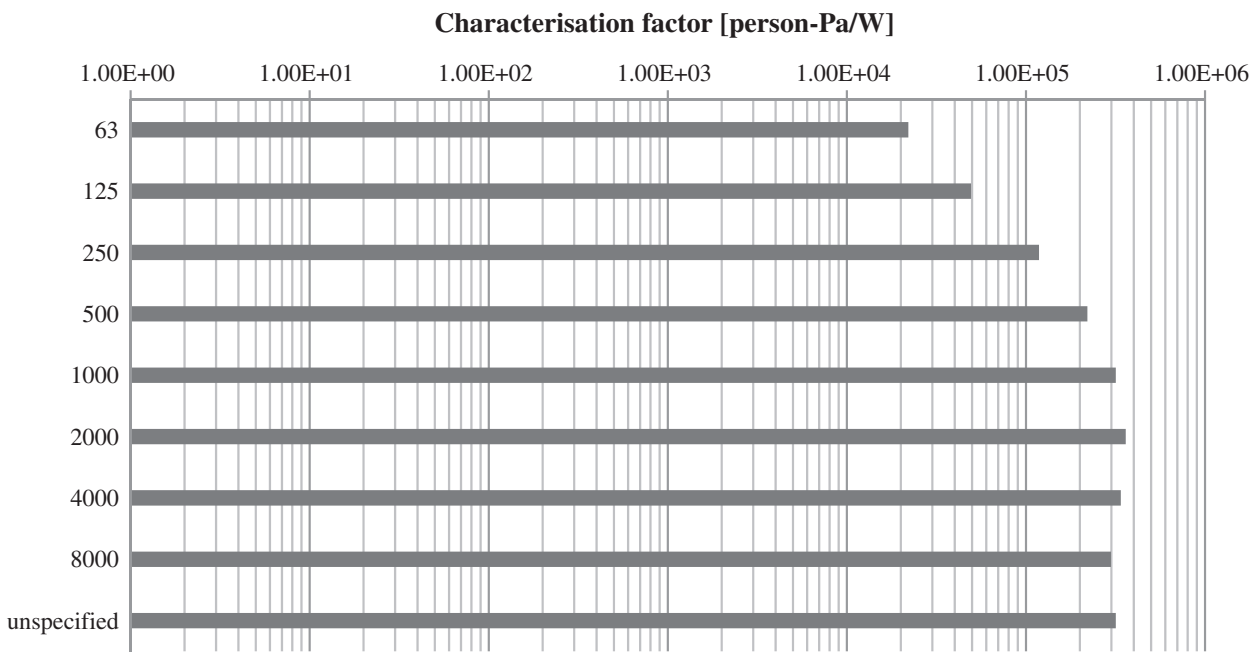

Fig. 3.3. Characterisation factor (in person-Pa/W) in a urban area during day time at eight centre-octaves and unspecified frequency. 


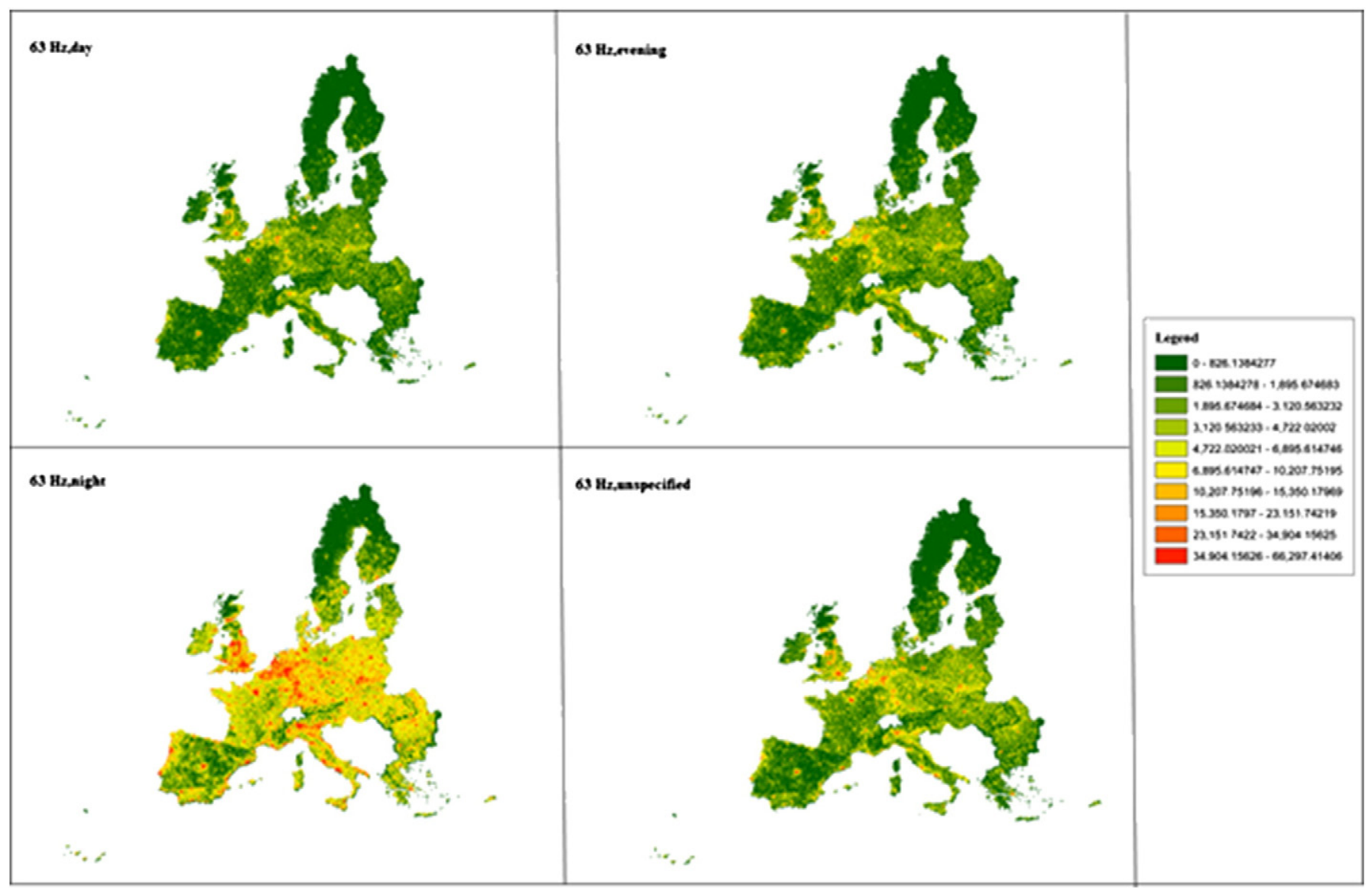

Fig. 3.4. Characterisation factor in map at $63 \mathrm{~Hz}$ for day, evening, night and unspecified time, at $63 \mathrm{~Hz}$ for EU27.

sound emissions to those of other emissions, it may be interesting to move to the endpoint level.

The human noise midpoint, $\mathrm{HN}_{\text {midpoint }}$, may be defined as

$\mathrm{HN}_{\text {midpoint }}=\sum_{i} \sum_{c} \sum_{f} \mathrm{~m}_{i, c, f} \times \mathrm{CF}_{i, c, f}$

where $\mathrm{m}_{i, c f}$ represents the inventory quantity in joules as calculated in Section 2.1, and $\mathrm{CF}_{i, c, f}$ refer to the characterisation factors, in person $\times$ pascal $\times \mathrm{s}$, for the relative specific $i, c$, and $f$ conditions of emission/exposure, as calculated and detailed in the previous sections.

In order to move to the endpoint, it is necessary to find the suitable conversion factor that converts the $\mathrm{HN}_{\text {midpoint }}$ in person $\times \mathrm{Pa} \times \mathrm{s}$, to a quantity in a unit, such as the DALY scale, which would allow for the comparison of noise impacts to other impacts to the human health area of protection. Hence, the human health endpoint in DALYs, $\mathrm{HH}_{\text {endpoint, }}$ may be calculated using a certain mid to end conversion factor, in $\mathrm{DALY} /$ person $\times \mathrm{Pa} \times \mathrm{s}$, as

$\mathrm{HH}_{\text {endpo int }}=\mathrm{HN}_{\text {midpoint }} \times \operatorname{mid}_{\text {to }}$ end

and, consequently,

$\operatorname{mid}_{\text {to }}$ end $=\frac{\mathrm{HH}_{\text {endpo int }}}{\mathrm{HN}_{\text {midpo int }}}$.

In order to quantify the mid_to_end conversion factor, it is necessary to refer to studies that have calculated the $\mathrm{HH}_{\text {endpoint }}$ for a certain geographical extent for which enough data is available, using a certain disability weight. A study from WHO (2011) on the burdens of disease from noise calculated the impact from environmental noise in DALYs from a considerable part of the EU, with some exceptions due to lack of exposure data. The study provides sufficient data for The Netherlands that can be used for the purpose of this contribution to quantify the conversion factor from midpoint human noise to endpoint human health. A total of 25,000 DALYs was calculated for the sole nocturnal exposure to noise with a disability weight of 0.07. For The Netherlands, Hollander et al. (1999) calculate the burden from environmental noise using a disability weight of 0.01 for severe annoyance and sleep disturbance. The study calculates a total of 28,690 DALYs lost due to residential noise as a function of the two combined environmental factors.

In order to calculate the mid_to_end conversion factor for the case of The Netherlands, the $\mathrm{HN}_{\text {midpoint }}$ needs to be calculated. To this end, we resorted to the spatially-explicit CFs described and calculated in Sections 2 and 3 of this contribution. By means of ArcGIS (ESRI, 2012), we calculated the $\mathrm{HN}_{\text {midpoint }}$ as a function of the background sound pressure L95 provided by EASA (2009). Due to data limitations, we considered the sound pressure level L95 as unspecified in terms of frequency, but differentiated per time (i.e. day, evening, night), and location (i.e. The Netherlands). The corresponding background sound power level was calculated as described in Supplementary material 1 of this contribution, and converted to a quantity in joules considering a time frame of 1 year. We did not consider here any specific functional unit or life cycle, but the sound power background level as calculated for The Netherlands as a function of all active static and moving sources of sound emissions, and normalised for a 1 year time frame.

A total of $7.82 \mathrm{E}+8$ person $\times \mathrm{Pa} \times \mathrm{s}$ was calculated: respectively, $3.18 \mathrm{E}+8$ for day, $2.67 \mathrm{E}+08$ for evening, and $1.96 \mathrm{E}+8$ for night emissions. For comparison, we calculated the value of mid_to_end 
applying Eq. (7) and using both the DALYs totals as calculated by Hollander et al. (1999) for day evening and night emissions, and the DALYs calculated by the WHO (2011) for the same geographical extent. The mid_to_end conversion factor as calculated using Hollander et al. (1999) amount to 2.9061E -5 DALY/person $\times$ Pa $\times$ s. Alternatively, a value of $2.13 \mathrm{E}-4 \mathrm{DALY} /$ person $\times \mathrm{Pa} \times \mathrm{s}$ was found applying the $\mathrm{WHO}$ (2011) assumptions for the evening condition.

\section{Conclusions, future agenda and potential expansion of the model}

This contribution proposes CFs which are immediately usable for the calculation of the impact of noise on humans at a midpoint level for any sound-emitting source, or combination of emitting sources. The methodology can be also applied with minor adjustments (e.g. frequency of interest, number of exposed subjects) to target systems other than human beings. The provided CFs can be implemented in any of the available LCA databases for impact-assessment systems.

The calculations are based on the assumption that the level of detail of CFs may be more or less of interest for practitioners and researchers, based on the amount of information that is available to them in a specific case. In total, 248 potential CFs were calculated (i.e. 32 spatial and 216 archetypal). Most life cycles will require the use of multiple CFs and even the combination of both spatial and non-spatial factors, based on the amount of data that is available and on the complexity of the system under study. The additional possibility of using user-defined values as input is allowed for the expansion of contexts of emissions and their adaptation to the specific needs.

The CFs are applicable to life-cycle aggregated sound emissions, measured in joules. The goal of the methodology is not to support the quantification of noise emissions in a life cycle of a complex product system. The procedure for obtaining these frequency-, time-, and location-specific data from $\mathrm{dB}$ that belong to individual unit processes has been described by Cucurachi et al. (2012). The standard databases with process data for LCA do not contain noise emissions, thus more investigations are needed at the inventory level to use the characterisation factors as elaborated in the present work. The literature provides already enough information to analyse specific cases, such as the proposed CNOSSOS report (European Commission, 2012). Nevertheless, we will demonstrate the use of the CFs in a future case study.

The $\mathrm{CFs}$ provided are in person $\times$ pascal $/ \mathrm{W}$, or $\mathrm{s}^{*} \mathrm{~m}^{-3}$. The measure provides a midpoint characterisation factor for the impact of noise on humans. The quantification of the amount of DALYs that are associated with the quantity expressed by the midpoint CFs may be used to provide a measure of the noise impacts at an endpoint level. The calculation of the DALYs associated with noise has been extrapolated from past studies by studying data from surveys on noise annoyance and level of disturbances (Miedema and Vos, 1998; Müller-Wenk, 2004; WHO, 2011). The conversion of person $\times$ pascal $\times s$ in the DALY scale was proposed with reference to the case of The Netherlands, for which sufficient information was available. Itsubo and Inaba (2008) developed
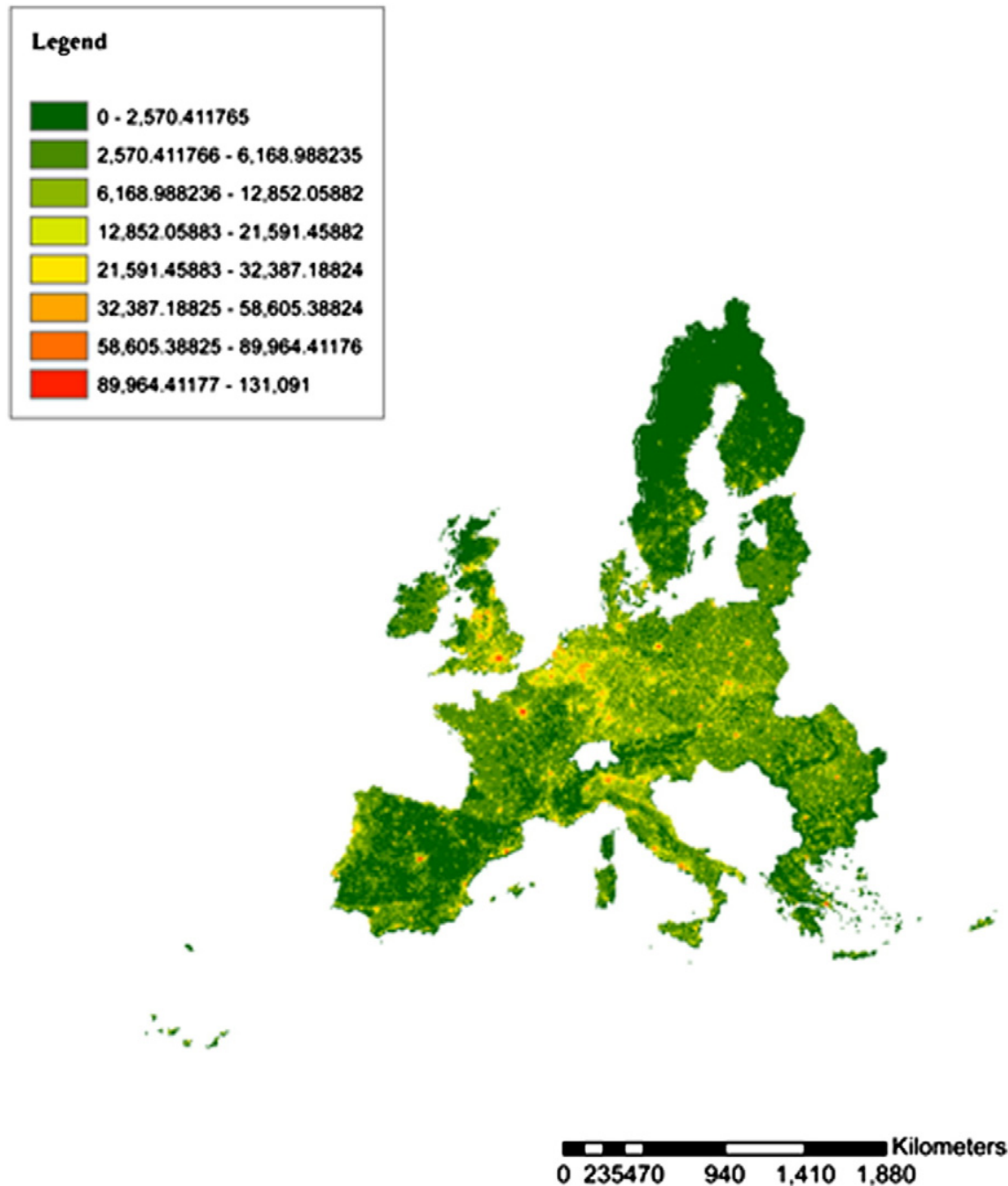

Fig. 3.5. Difference between $\mathrm{CF}$ at $63 \mathrm{~Hz}$ night and CF at $63 \mathrm{~Hz}$ unspecified. 
Table 3.2

Description of uncertain input factors.

\begin{tabular}{|c|c|c|c|c|}
\hline \multicolumn{5}{|c|}{ Statistical definition of parameters } \\
\hline $\begin{array}{l}\text { Parameter } \\
\text { [unit] }\end{array}$ & Symbol & Distribution & $\begin{array}{l}\text { Mean }{ }^{\mathrm{a}} \text { or left } \\
\text { bound }^{\mathrm{b}} \text { or discrete } \\
\text { values }^{\mathrm{c}}\end{array}$ & $\begin{array}{l}\text { Standard } \\
\text { deviation }^{\mathrm{a}} \\
\text { or right bound }^{\mathrm{b}} \text { or } \\
\text { discrete values }^{\mathrm{c}}\end{array}$ \\
\hline $\begin{array}{l}\text { Ambient } \\
\text { sound } \\
\text { power level } \\
{[\mathrm{dB}]}\end{array}$ & Lw & Normal & 20 & 10 \\
\hline $\begin{array}{l}\text { Frequency } \\
{[\mathrm{Hz}]}\end{array}$ & $\mathrm{fm}$ & $\begin{array}{l}\text { Discrete } \\
\text { (equiprobable) }\end{array}$ & $\begin{array}{l}{[63 ; 125 ; 250 ; 500 ;} \\
1000 ; 2000 ; 4000 ; \\
8000]\end{array}$ & $\begin{array}{l}{[0.1 ; 0.1 ;} \\
0.15 ; 0.15 ; 0.15 ; \\
0.15 ; 0.1 ; 0.1]\end{array}$ \\
\hline $\begin{array}{l}\text { Temperature } \\
\text { [deg] }\end{array}$ & $\mathrm{T}$ & Uniform & 0 & 25 \\
\hline $\begin{array}{l}\text { Relative } \\
\text { humidity [\%] }\end{array}$ & $\mathrm{Rh}$ & Uniform & 10 & 90 \\
\hline Pressure [kPa] & $\mathrm{P}$ & Uniform & 10 & 101325 \\
\hline $\begin{array}{l}\text { Average } \\
\text { propagation } \\
\text { height [m] }\end{array}$ & $\mathrm{h}$ & LogUniform & 2 & 8 \\
\hline Distance [m] & $\mathrm{d}$ & LogUniform & 5 & 50 \\
\hline $\begin{array}{l}\text { Reference area } \\
{\left[\mathrm{km}^{2}\right]}\end{array}$ & $\mathrm{S}$ & LogUniform & 5 & 30 \\
\hline $\begin{array}{l}\text { Number of } \\
\text { people }\end{array}$ & $\mathrm{Nf}$ & Normal & 1000 & 300 \\
\hline $\begin{array}{l}\text { Directivity } \\
{[\mathrm{dB}]}\end{array}$ & $\mathrm{D}$ & Discrete & {$[3 ; 6 ; 9]$} & {$[0.7 ; 0.15 ; 0.15]$} \\
\hline $\begin{array}{l}\text { Frequency } \\
\text { penalty }[\mathrm{dB}]\end{array}$ & $\alpha$ & Discrete & $\begin{array}{l}{[-26.2 ;-16.1 ;} \\
-8.6 ;-3.2 ; 0 ; 1.2 \\
1 ; 1.1]\end{array}$ & $\begin{array}{l}{[0.1 ; 0.1 ; 0.15 ;} \\
0.15 ; 0.15 ; 0.15 \\
0.1 ; 0.1]\end{array}$ \\
\hline $\begin{array}{l}\text { Time penalty } \\
{[\mathrm{dB}]}\end{array}$ & $\beta$ & Triangular $^{\mathrm{d}}$ & {$[0 ; 5 ; 10]$} & - \\
\hline $\begin{array}{l}\text { Ground } \\
\text { composition } \\
\text { coefficient }\end{array}$ & G & Uniform & 0 & 1 \\
\hline
\end{tabular}

a The mean and standard deviation are provided in the case of normal, lognormal, and loguniform distributions.

$\mathrm{b}$ Left bound and right bound are provided for uniform distributions.

c Discrete values are provided for discrete and triangular distributions.

d The time penalty $\beta$ was assumed triangularly distributed, according to the pessimistic approach used in the calculations, according to which a higher penalty was attributed to emissions taking place at night.

a damage function for noise impacts associating the corresponding value in DALYs with a sound energy emission in joules for Japan. These results may provide an interesting basis for comparison, once suitable inventory data is available at the right level of geographical specification also for Japan. We intend to go towards this direction, also making use of the results available in the literature of the impacts of noise on health (see for instance, Fyhri and Klæboe, 2009; Pirrera et al., 2010). The assumption of linearity allowed for the quantification of a conversion factor, but may introduce uncertainty that needs to be further investigated into the calculations. The comparison of results in a complete case study involving also the study of other environmental impacts in a complete product system is under development within the LC-IMPACT project of the EU (www.lc-impact.eu) and will certainly be a test bed for our methodology.

The result of the global sensitivity analysis allowed for a better comprehension of the model structure when parameters are independent. The first order and total order sensitivity indices that we calculated already provide an idea of the areas where investments may be made to reduce uncertainty. We saw, in fact, that it is risky to fix some values to a central value without carefully thinking over their contribution to the variance of the output and the high-order interactions between a parameter and the others. The results provide a good basis on which to expand the analysis of the framework and through which to improve data collection. The limited availability of data (e.g. only one trustable source for background sound levels) and the highly-localised nature of the impacts may pose a challenge to the collection of information for some of the parameters. As stated in Borgonovo et al. (2012), without a proper sensitivity analysis one is exposed to the so-called black-box effect, namely the risk of not fully understanding the behaviour of the model on which analyses and decisions are based. The use of global sensitivity analysis techniques should become standard practice also in the LCIA development. Several applications of sensitivity analysis techniques have, in fact, improved the understanding and the performance of complex environmental systems (see, for instance, Fassó et al., 2003; Borgonovo et al., 2012). As was shown in the case of noise, the development of spatially-explicit CFs does not statim reduce uncertainties. In our case, the lack of data did not allow us to go to a finer resolution than $10 \mathrm{~km}^{2}$. In order to also evaluate the right scale of spatial definition for the development of maps of CFs, a global sensitivity analysis should be conducted. The application of sensitivity analysis to environmental risks and impacts may have to handle a large set of input data, especially in the case of spatially and temporally-variable systems. Techniques have been developed to overcome such issues through the use of meta-models (Marrel et al., 2011). In this context, a Gaussian process model as developed by Marrel et al. (2011) can and should be used to calculate sensitivity indices (or index maps) and process uncertainties also in the case of high dimensional output of a model, as are characterisation maps in LCIA.

\section{Acknowledgements}

The present research was funded by the European Commission under the 7th Framework Programme on Environment; ENV.2009.3.3.2.1: LCIMPACT-Improved Life Cycle Impact Assessment methods (LCIA) for better sustainability assessment of technologies, grant agreement number 243827. The authors would like to thank Sandra Torras Ortiz from the University of Stuttgart, in Germany, for the valuable contribution in the gathering of part of the GIS data, and Nicolas Davin from NaturalisBiodiversity Center, in Leiden, The Netherlands, for the precious tips and hints on data handling in GIS. Special thanks also to Novella De Matteis for the help with the editing of the manuscript. Warm thanks also go to Willem Franken from EASA, who permitted access to the full documentation of the BANOERAC project, and to Dr. Enrico Benetto and Dr. Olivier Baume from the CRP Henry Tudor in Luxembourg, who provided important comments for the improvement of this contribution.

\section{Appendix A. Supplementary data}

Supplementary data to this article can be found online at http://dx. doi.org/10.1016/j.scitotenv.2013.07.080.

Table 3.3

First and total order sensitivity indices.

\begin{tabular}{|c|c|c|c|c|c|c|}
\hline \multirow[b]{2}{*}{ Input variable $\left(\mathrm{X}_{\mathrm{j}}\right) /$ model output $(\mathrm{Y})$} & \multicolumn{3}{|c|}{$\begin{array}{l}\text { First order indices } \\
\left(\mathrm{S}_{\mathrm{j}}\right)\end{array}$} & \multicolumn{3}{|c|}{$\begin{array}{l}\text { Total order indices } \\
\left(\mathrm{S}_{\mathrm{Tj}}\right)\end{array}$} \\
\hline & $\mathrm{EF}$ & $\mathrm{FF}$ & $\mathrm{CF}$ & $\mathrm{EF}$ & $\mathrm{FF}$ & $\mathrm{CF}$ \\
\hline Lw & 0.050 & 0.129 & 0.118 & 0.436 & 0.804 & 0.746 \\
\hline Freq & 0.092 & 0.005 & 0.106 & 0.791 & 0.102 & 0.874 \\
\hline $\mathrm{T}$ & 0.075 & 0.071 & 0.032 & 0.689 & 0.655 & 0.354 \\
\hline $\mathrm{P}$ & 0.035 & 0.077 & 0.091 & 0.406 & 0.761 & 0.778 \\
\hline $\mathrm{Rh}$ & 0.083 & 0.045 & 0.042 & 0.750 & 0.477 & 0.460 \\
\hline $\mathrm{h}$ & 0.066 & 0.017 & 0.067 & 0.625 & 0.243 & 0.626 \\
\hline $\mathrm{d}$ & 0.061 & 0.103 & 0.108 & 0.554 & 0.857 & 0.882 \\
\hline$S$ & 0.080 & 0.042 & 0.059 & 0.719 & 0.330 & 0.584 \\
\hline $\mathrm{Nf}$ & 0.035 & 0.023 & 0.084 & 0.404 & 0.325 & 0.723 \\
\hline $\mathrm{D}$ & 0.075 & 0.248 & 0.113 & 0.600 & 0.907 & 0.891 \\
\hline$\alpha$ & 0.099 & 0.088 & 0.002 & 0.814 & 0.768 & 0.799 \\
\hline$\beta$ & 0.217 & 0.009 & 0.108 & 0.911 & 0.217 & 0.883 \\
\hline G & 0.033 & 0.028 & 0.048 & 0.386 & 0.329 & 0.477 \\
\hline
\end{tabular}




\section{References}

Annoni A, Luzet C, Gubler E. Map projections for Europe. Institute for Environment and Sustainability; 2003 (Available at: http://mapref.org/LinkedDocuments/ MapProjectionsForEurope-EUR-20120.pdf. Accessed on the: 28-06-2012).

Babisch W. Transportation noise and cardiovascular risk: updated review and synthesis of epidemiological studies indicate that the evidence has increased. Noise and Health 2006;8(30):1.

Borgonovo E, Castaings W, Tarantola S. Model emulation and moment-independent sensitivity analysis: an application to environmental modelling. Environ Model Softw 2012;34:105-15.

Burrough PA, McDonnell RA. Principles of geographical information systems. Oxford, UK: Oxford University Press; 1998.

Caflisch RE. Monte Carlo and quasi-Monte Carlo methods. Acta Numerica, 7. Cambridge University Press; 19981-49.

Concha-Barrientos M, Campbell-Lendrum D, Steenland K. Occupational noise. Assessing the burden of disease from work-related hearing impairment at national and loca levels. Geneva: World Health Organization; 2004.

Couclelis $\mathrm{H}$. The certainty of uncertainty: GIS and the limits of geographic knowledge Trans GIS 2003;7:165-75.

Cucurachi S, Heijungs R, Ohlau K. Towards a general framework for including noise impacts in LCA. Int J Life Cycle Assess 2012;4(17):471-87.

Curran MA. Life cycle assessment handbook: a guide for environmentally sustainable products. USA: Wiley; 2012.

EASA - Environmental Aviation Safety Agency. Background noise level and noise level from en route aircraft final report. Available online at http://www.easa.europa.eu/ rulemaking/studies-and-research-activities.php, 2009. [Accessed on 05-06-2012]

ESRI. ArcGIS desktop: release 10. Computer Software. Redlands, CA: Environmenta Systems Research Institute; 2011.

ESRI. ArcGIS Desktop: Release 11. Redlands. Redlands, CA: Environmental Systems Research Institute; 2012.

European Commission. Common NOise ASSessment MethOdS in EU (CNOSSOS-EU). Available online at: http://circa.europa.eu/Public/irc/env/noisedir/library?l=/ material_mapping/cnossoseu/cnossoseu_technical/kick-off_15-16nov2010/ cnossos-eu_9nov2010pdf/_EN_1.0_\&a=d, 2012. [Accessed on: August 2012].

Eurostat, Euroindicators. Available online at: http://epp.eurostat.ec.europa.eu/portal/page/ portal/eurostat/home/, 2007. [Accessed on the: 21-08-2012].

Fassó A, Esposito A, Porcu E, Reverberi AP, Veglió F. Statistical sensitivity analysis of packed column reactors for contaminated wastewater. Environmetrics 2003;14:743-59.

Fyhri A, Klæboe R. Road traffic noise, sensitivity, annoyance and self-reported health-a structural equation model exercise. Environ Int 2009;35(1):91-7.

Heijungs R. On the use of units in LCA (4 pp). Int J Life Cycle Assess 2005;10(3):173-6.

Heijungs R, Suh S. The computational structure of life cycle assessment, vol. 11. Springer; 2002.

Heijungs R, Guinée JB, Huppes G, Lankreijer RM, Udo de Haes HA, Wegener Sleeswijk A, et al. Environmental life cycle assessment of products. I. Guide, October 1992 Il. Backgrounds, October 1992. Leiden: CML; 1992 (226 pp.).

Hijmans RJ, Cameron SE, Parra JL, Jones PG, Jarvis A. Very high resolution interpolated climate surfaces for global land areas. Int J Climatol 2005;25:1965-78.

Hollander AED, Melse JM, Lebret E, Kramers PG. An aggregate public health indicator to represent the impact of multiple environmental exposures. Epidemiology-Baltimore 1999;10(5):606-17.

ILCD - International Reference Life Cycle Data System Handbook - General guide for Life Cycle Assessment - Detailed Guidance. European Commission, Joint Research Centre Institute for Environment and Sustainability. Luxemburg: Publications Office of the European Union; 2010.
ISO. ISO 9613-1: International Standard: Acoustics - attenuation of sound during propagation outdoors - part 1: calculation of the absorption of sound by the atmosphere. Geneva: ISO; 1993.

ISO. ISO 9613-2: International Standard: Acoustics - attenuation of sound during propagation outdoors - part 2: a general method of calculation. Geneva: ISO; 1996.

ISO. ISO 14040: Environmental Management - Life Cycle Assessment - Principles and Framework. Geneva: ISO; 2000.

Itsubo RN, Inaba A. Noise impact assessment in LCA: damage function of road transport noise in Japan. Available online in Japanese at http://www.aist-riss.jp/main/modules/ groups_alca/content0005.html?ml_lang=en, 2008. [Accessed on the: 18-05-2012].

Jarvis A, Reuter HI, Nelson A, Guevara E. Hole-filled SRTM for the globe Version 4, available from the CGIAR-CSI SRTM 90m Database. Available online at: http://www.cgiar-csi.org/ 2010/03/108/uot, http:/srtm.csi.cgiar.org, http:/srtm.csi.cgiar.org, 2008. [Accessed on: 1112 2012].

Jolliet O, Dubreuil A, Gloria T, Hauschild M. Progresses in life cycle impact assessment within the UNEP/SETAC life cycle initiative. Int J LCA 2005;10(6):447-8.

Marrel A, Iooss B, Jullien M, Laurent B, Volkova E. Global sensitivity analysis for models with spatially dependent outputs. Environmetrics 2011;22(3):383-97.

Miedema HME, Vos H. Exposure-response relationships for transportation noise. J Acoust Soc Am 1998; 104:3432-45.

Müller-Wenk R. A method to include in LCA road traffic noise and its health effects. Int J Life Cycle Assess 2004:9:76-85.

Pennington DW, Potting J, Finnveden G, Lindeijer E, Jolliet O, Rydberg T, et al. Life cycle assessment. Part 2: current impact assessment practice. Environ Int 2004;30(5): 721-39.

Pirrera S, De Valck E, Cluydts R. Nocturnal road traffic noise: a review on its assessment and consequences on sleep and health. Environ Int 2010;36(5):492-8.

Rebitzer G, Ekvall T, Frischknecht R, Hunkeler D, Norris G, Rydberg T, et al. Life cycle assessment. Part 1: framework, goal and scope definition, inventory analysis, and applications. Environ Int 2004;30(5):701-20.

Saha S, Moorthi S, Pan HL, Wu X, Wang J, Nadiga S, et al. The NCEP climate forecast system reanalysis. Bull Am Meteorol Soc 2010;91:1015-57.

Saltelli A, Chan KS, Tarantola S. Sensitivity analysis of model output: an improvement of the FAST method. Joint Research Center; 1997.

Saltelli A, Tarantola S, Campolongo F, Ratto M. Sensitivity Analysis in Practice, a Guide to Assessing Scientific Models. New York: Wiley; 2004.

Saltelli A, Ratto M, Andres T, Campolongo F, Cariboni J, Gatelli D, et al. Global sensitivity analysis: the primer. USA: Wiley-Interscience; 2008.

Schroeder M. Springer handbook of acoustics. New York, USA: Springer; 2007.

Stewart CM, Russel WA, Luz GA. Can population density be used to determine ambient noise levels? Berlin, Germany: Forum Acusticum; 1999.

Stewart J, McManus F, Rodgers N, Weedon V, Bronzaft A. Why noise matters: a worldwide perspective on the problems, policies and solutions. Abington, Oxon, UK: Routledge; 2011.

Tarantola S, Giglioli N, Jesinghaus J, Saltelli A. Can global sensitivity analysis steer the implementation of models for environmental assessments and decision-making? Stoch Environ Res Risk A 2002;16:63-76.

US EPA. Population distribution of the United States as a function of outdoor noise level, Report 550/9-74-009; 1974.

WHO Occupational exposure to noise evaluation, prevention and control. In: Goelzer Berenice, Hansen Colin H, Sehrndt Gustav A, editors. Copenhagen: World Health Organization; 2001. [Available online at: http://www.who.int/occupational_health/ publications/occupnoise/en/index.html. Accessed on: 2911 2012].

WHO. Burden of disease from environmental noise - quantification of healthy life years lost in Europe. Copenhagen: World Health Organization; 2011. 